Mendes Pontes, E.T., Silva Campos, G., Bezerra de Carvalhoo, A. (2018): "Geotecnologias, cartografia digital e geoprocessamento aplicados ao ensino de geografia e disciplinas afins: uma experiência de extensão no semiárido cearense", GeoFocus (Articulos), no 21, p. 145-167. ISSN: 1578-5157 http://dx.doi.org/10.21138/GF.570

\title{
GEOTECNOLOGIAS, CARTOGRAFIA DIGITAL E GEOPROCESSAMENTO APLICADOS AO ENSINO DE GEOGRAFIA E DISCIPLINAS AFINS: UMA EXPERIÊNCIA DE EXTENSÃO NO SEMIÁRIDO CEARENSE
}

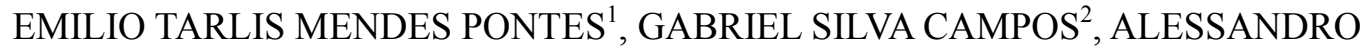 \\ BEZERRA DE CARVALHOO ${ }^{3}$ \\ ${ }^{1}$ Instituto Federal do Ceará - IFCE \\ Rua Estevão Remígio de Freitas, 1145 - Monsenhor Otávio, Limoeiro do Norte - CE, \\ 62930-000, Brasil \\ tarlispontes@gmail.com \\ ${ }^{2}$ Universidad Autónoma de Madrid \\ Ciudad Universitaria de Cantoblanco, 28049 Madrid, España \\ gabrielsilva.campos@gmail.com \\ ${ }^{3}$ Universidade Estadual Vale do Acaraú - UVA \\ Av. da Universidade, 850 - Campus da Betânia, Sobral - CE, 57030-680, Brasil \\ ale17.carvalho@gmail.com
}

\section{RESUMO}

$\mathrm{O}$ advento das inovações tecnológicas tornou imperativo que Instituições de ensino se coadunassem com as evoluções que impactam o cotidiano pós-moderno. É perceptível o aperfeiçoamento dos recursos didáticos empregados pelos pesquisadores em suas atividades: ferramentas utilizadas são avanços que adentraram nas escolas facilitando a prática do ensino/pesquisa. Destarte, são necessárias outras metodologias complementando o ofício de forma qualificada e instrutiva. Para tanto, é preciso ter laboratórios de informática constantemente atualizados e acessíveis. Outro motivo é a falta de formação no manuseio de Sistemas de Informação Geográfica, sites, programas computacionais, GPS e softwares afins, que processam, cotejam, armazenam e geram produtos finais. Assim, foi realizado um projeto de extensão no Instituto Federal do Ceará, campus Crateús, em 2016. O presente artigo é oriundo desta experiência e discute seus êxitos, replicabilidade e desafios.

Palavras chave: Geotecnologias, geografia, geoprocessamento, SIG, extensão.

GEOTECHNOLOGIES, DIGITAL CARTOGRAPHY AND GEOPROCESSING APPLIED TO GEOGRAPHY TEACHING AND RELATED DISCIPLINES: AN EXPERIENCE OF EXTENSION IN THE SEMIARID CEARENSE.

\section{ABSTRACT}

With the advent of technological innovations, educational institutions have to be in line with the evolutions that impact postmodern everyday life. Therefore, the improvement of the didactic resources employed by the researchers in their activities is noticeable: some tools that 
Mendes Pontes, E.T., Silva Campos, G., Bezerra de Carvalhoo, A. (2018): “Geotecnologias, cartografia digital e geoprocessamento aplicados ao ensino de geografia e disciplinas afins: uma experiência de extensão no semiárido cearense", GeoFocus (Articulos), no 21, p. 145-167. ISSN: 1578-5157 http://dx.doi.org/10.21138/GF.570

have entered schools were real breakthroughs, facilitating the practice of teaching/research. However, other methodologies are necessary to complement the academic work in a qualified and instructive way. It is also necessary to have constantly updated and accessible computer labs. Another aspect is the lack of training in Geographic Information Systems, websites, GPS and related software which process, collate, store and generate final products. Thus, an extension project was carried out at the Instituto Federal do Ceará, Crateús campus, in 2016. This article stems from that experience and discusses its successes, replicability and challenges.

Keywords: Geotechnologies, geography, geoprocessing, GIS, extension.

\section{Introdução}

As relações do ser humano com o espaço geram alterações quantificáveis. O registro final deste encadeamento é capaz de ser transformado em dados e estes se tornam objetos de estudos e recursos aplicados na Geografia e outras áreas e saberes. A necessidade de referenciar determinada localização está presente na História da humanidade. Tal condição resultou como motivação para a construção de diversos conhecimentos que serviram de base e ferramentas para a estruturação das primeiras premissas da astronomia, geometria, geologia e são aplicadas em vários ramos da ciência sendo que, desde o século passado, suas imbricações com as tecnologias modernas revolucionaram as formas de produzir o espaço.

As tecnologias emergem e impactam variadas áreas de cotidiano, incluindo as tarefas desenvolvidas no Ensino-Pesquisa-Extensão (E-P-E). É perceptível a evolução dos recursos didáticos empregados pelos educadores em suas atividades: ferramentas frequentemente utilizadas e que são exemplos de avanços tecnológicos que adentraram nas escolas/institutos para facilitar a prática da tríade E-P-E.

Concebe-se que a Extensão, em íntima correlação com o Ensino e Pesquisa, carece - no caso específico nos campi do Instituto Federal do Ceará (IFCE) do interior do Estado - de contínua implantação e/ou modernização de seus laboratórios de pesquisa e inovação, tanto pela conjuntura histórica de desigualdades político-econômicas que privilegiavam apenas a Capital (Fortaleza), como pela deficiência na formação de profissionais qualificados. A interiorização dos IFCE é uma política que está sendo apta para ir sanando tais carências e merece projetos nesse viés.

Outrossim, urge que sejam qualificados os equipamentos laboratoriais existentes para que essa política exitosa possa ter um nível de excelência robusto, desenvolvendo a pesquisa com equipamentos atuais e em conexão com as tendências globais. Ademais, a constituição e integração em networks é imprescindível para o aprimoramento, intercâmbio e formalização de parcerias, seja no âmbito de outros campi do IFCE como com outras Instituições de Ensino Superior no Brasil. Logo, a proposta de um projeto de extensão também tem como característica o estabelecimento de redes de colaboração com grupos de pesquisas devidamente cadastrados no Conselho Nacional de Desenvolvimento Científico e Tecnológico (CPNq) e de reconhecida atuação acadêmica, cujos intercâmbios entre pesquisadores favorecem o crescimento de bolsistas e da pesquisa.

A concepção deste projeto, embora possua matriz na Geografia, tem caráter inter e multidisciplinar e potencializou a pesquisa em diversas áreas correlatas no tocante às inovações tecnológicas, sendo relevante para o desenvolvimento científico no campus de implantação, cujos resultados são aplicados diretamente nos trabalhos finais em variados projetos de pesquisas. Atualmente, as aplicações das ciências geográficas possuem uma plêiade de possibilidades de utilização, apoio e correlação com outras grandes áreas do conhecimento, 


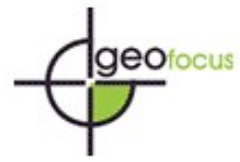

Mendes Pontes, E.T., Silva Campos, G., Bezerra de Carvalhoo, A. (2018): “Geotecnologias, cartografia digital e geoprocessamento aplicados ao ensino de geografia e disciplinas afins: uma experiência de extensão no semiárido cearense", GeoFocus (Articulos), no 21, p. 145-167. ISSN: 1578-5157 http://dx.doi.org/10.21138/GF.570

aspecto este que fomenta parcerias com distintas Instituições do Ensino, Organizações NãoGovernamentais, empresas públicas ou privadas etc.

Baseado nas definições da PINTEC (Pesquisa de Inovação) do IBGE (Instituto Brasileiro de Geografia e Estatística), compreende-se por atividades inovativas aquelas que se referem aos esforços empreendidos no desenvolvimento e implementação de produtos e processos novos ou aperfeiçoados. A pesquisa mensura estes esforços por meio de uma escala de importância para a instituição no qual está sendo trabalhado tais atividades.

Alguns fatores dificultam a aplicação das geotecnologias no E-P-E, como a subutilização de laboratórios de informática. Outro motivo é a deficiência de formação dos professores/pesquisadores/alunos com relação ao conhecimento e manuseio de Sistema de Informação Geográfica e softwares afins, tendo em vista que os Parâmetros Curriculares Nacionais apoiam a inserção de tecnologias no ambiente escolar. Tais panoramas compõem a proposta desse projeto no IFCE. Esse potencial ampara-se na literatura especializada, como visto em Fonseca (2004) e Pinto; Garcia; Letichevsky (2006).

Desta forma, a partir do edital "Programa Institucional de Apoio a Projetos de Extensão PAPEX/PROEXT 2016", foi submetido, aprovado, financiado, executado e finalizado o projeto intitulado "Geotecnologias, cartografia digital e geoprocessamento aplicados ao ensino de geografia e disciplinas afins", no campus IFCE - Crateús (Figura 1), em 2016, doravante o escopo desse artigo.

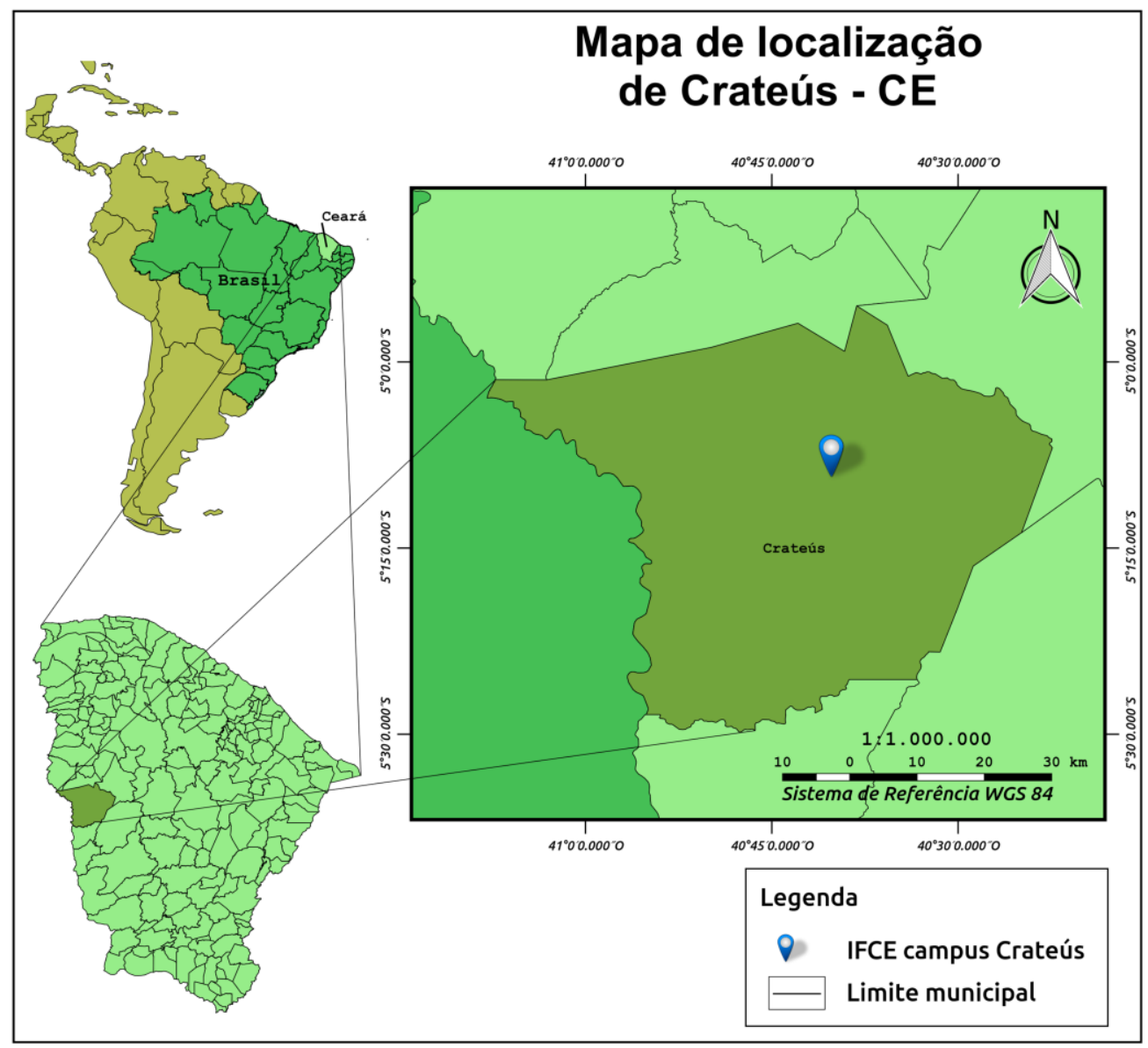

Figura 1: Localização do município de Crateús - Ceará.

Fonte: os autores, 2017. 
Mendes Pontes, E.T., Silva Campos, G.., Bezerra de Carvalhoo, A. (2018): "Geotecnologias, cartografia digital e geoprocessamento aplicados ao ensino de geografia e disciplinas afins: uma experiência de extensão no semiárido cearense”, GeoFocus (Artículos), no 21, p. 145-167. ISSN: 1578-5157 http://dx.doi.org/10.21138/GF.570

A justificativa desse projeto baseia-se na constatação de que laboratórios de informática das escolas de ensino fundamental e médio são subutilizados para as aulas de geografia e ciências afins, o que gera carência de novas metodologias e composição de produtos finais (mapas, imagens etc). Do mesmo modo, as geotecnologias como instrumentos pedagógicos são meios didáticos em constante evolução, mas que precisam ser absorvidas de modo a integrar e unir tecnologia e ciência, compondo uma ferramenta de aprendizado para professores e alunos.

O projeto teve como objetivo geral proporcionar formação continuada baseada na multiinterdisciplinaridade e nas metodologias pedagógicas para professores da rede municipal de ensino Crateús, alunos/docentes do IFCE e demais interessados a partir das múltiplas ferramentas e técnicas advindas das geotecnologias, interligando as atividades de ensino e pesquisa com estas notórias demandas locais. Sendo assim, os objetivos específicos, foram, a saber: a) Desenvolvimento de práticas pedagógicas através da interpretação e manuseio cartográfico digital associados às geotecnologias; b) Introduzir a utilização de softwares e geotecnologias na elaboração de mapas e produtos finais para uso em sala de aula ou Trabalho de Conclusão de Curso; c) Auxiliar no desenvolvimento de geotecnologias como atividades pedagógicas que aproximem e incrementem os programas de ensino com o cotidiano dos alunos; d) Despertar nos educadores/cursistas o interesse pela pesquisa científica no âmbito das geotecnologias; e) Dinamização de conteúdos didáticos através do uso das geotecnologias; f) Aplicação do conteúdo do curso na prática docente do cursista, acompanhando sua implementação em sala de aula; g) Aprimorar a confecção de mapas para usos acadêmicos e de ensino básico.

Ao traçar as justificativas, necessidades e benefícios que esse projeto proporcionou para a comunidade de Crateús, faz-se necessário considerar que este campo de conhecimento possui reverberações em diversos centros acadêmicos de excelência ao redor do mundo. Nas últimas décadas, com o advento das geotecnologias, multiplicaram-se as experiências internacionais baseadas na introdução, aplicação e aperfeiçoamento da cartografia digital aplicada às geotecnologias e à ciência geográfica.

Para contextualizar e alinhar a problemática com tais experiências em outras partes do mundo, destaca-se que há uma profusão de seminários, congressos e eventos realizados na temática em tela e adjacentes. Em países tidos como desenvolvidos, essas questões já vêm sendo construídas nas últimas décadas, como o Seminário "Internet-Based Cartographic Teaching and Learning: Atlases, Map Use, and Visual Analytics", realizado em Madrid, 2005, que trouxe ao debate experiências de profissionais dos Estados Unidos, Bulgária, Canadá, Reino Unido, Polônia, Israel etc, onde a perspetiva de realização de treinamento em em Sistemas de Informações Geográficas no ensino era uma preocupação em perspetiva real, portanto havia a prerrogativa por busca de alternativas, suportes pedagógicos e introdução de softwares no ensino.

É relevante frisar que as dificuldades encontradas no semiárido brasileiro não destoam tanto de outros países. Gómez (2013), em estudo realizado na Carolina do Norte, Estados Unidos, adverte que a herança deixada nas tradicionais formas de ensino ainda proporcionam nesse país - cujo progresso tecnológico é profícuo - um enrijecimento que pode trazer dificuldades nos avanços da disciplina. Especificamente, Gómez introduziu conceitos e práticas de GPS em atividades escolares recreativas para auxiliar as correlações do ensinoaprendizagem, concluindo que tão somente o livro didático não cobriria suficientemente as novas tecnologias em ascensão. A autora chegou a uma conclusão cujo teor precisa ser exposto: "When schools eliminate and sanitize (a one size fits all approach) students' experiences with technology, they are denying them an important opportunity to connect the information they are learning to the very fabric of their cultural understanding" (GÓMEZ, 2013, p. 44), ou seja, é 
Mendes Pontes, E.T., Silva Campos, G., Bezerra de Carvalhoo, A. (2018): “Geotecnologias, cartografia digital e geoprocessamento aplicados ao ensino de geografia e disciplinas afins: uma experiência de extensão no semiárido cearense”, GeoFocus (Artículos), no 21, p. 145-167. ISSN: 1578-5157 http://dx.doi.org/10.21138/GF.570

necessário sair da acomodação das práticas tradicionalistas e investir nesse tecido cultural tecnológico pós-moderno, sob o risco de deixar gerações alienadas do processo tecnológico que as ciências geográficas e afins tem a oferecer.

Na Bulgária, um país que não é um potência tecnológica como o caso acima citado, encontram-se experiências que confluem com a problemática aqui tratada. Bandrova (2005, 2010) considera que nesse país, com as dificuldades para difusão de equipamentos cartográficos de ponta, as práticas voltadas às geotecnologias tem proporcionado ganho de qualidade no ensino. Suas propostas fincam-se no marco "from paper to virtual map". A constatação é que os alunos que são capacitados e conhecem as ferramentas digitais podem gerar legados imediatos, tais como a popularização da cartografia outrora relegada a mapas tradicionais e de pouco uso; a facilidade da utilização de materiais cartográficos na educação em distintos lugares ao mesmo tempo, ou seja, a digitalização leva à amplitude de divulgação e proporciona know-how; salvar e proteger os arquivos nacionais; criação de web sites com produtos modernos sobre a cartografia desse país.

A estratégia feito por profissionais na Bulgária através da introdução da cartografia digital e do geoprocessamento nas escolas, afirma Bandrova (2010), tem efetivamente transformado o ensino. Assim como no semiárido brasileiro, os relatos búlgaros mostram que mudanças são necessárias, pois salas de aula repletas de mapas desatualizados e sem interatividade configuram ferramentas descontextualizadas e sem capacidade de proporcionar excelência no aprendizado nos atuais conteúdos escolares.

Uma equipe de professores da Universidade de Zaragoza (Espanha), levou a cabo um projeto similar na cidade de Badajoz (Extremadura), sendo executado em duas etapas: 2013/2014 e 2014/2015 (DE LA RIVA, J., IBARRA, P., MONTORIO, R. \& RODRIGUES, M, 2015). Examinando essa experiência encontra-se algumas similitudes. O ponto de partida do trabalho constituiu-se na análise para radiografar a situação em que se encontrava o ensino de geografia no nível Fundamental e Médio (Educación Secundaria Obligatoria y Bachillerato). A primeira constatação foi que o modelo encontrado era totalmente academicista e tradicionalista, baseado unicamente no uso de textos e mapas, com atividades restritivas à sala de aula. Com isso, esse grupo de investigadores concluiu que o modelo necessita evoluir para uma geografia prática que leva a uma percepção da relação do cidadão com o espaço em que vive, tendo como recurso principal o uso das Tecnologias da Informação Geográfica através de atividades internas e externas. Um aspecto destacado foi a multidisciplinaridade. A organização que antecedeu a execução foi composta por professores de outras disciplinas que participaram das atividades de formação e posteriormente aplicaram o conteúdo dentro de suas respectivas disciplinas. Desta maneira, as temáticas foram trabalhadas de forma critica onde a inovação, a experimentação e o uso das tecnologias desenvolviam o pensamento criativo e empreendedor, cujas propostas estavam contextualizadas em situações reais e o aluno passara de uma postura meramente passiva na recepção da informação, passando a ser sujeito ativo em busca de soluções.

A grade curricular foi outro problema destacado na pesquisa. O curriculum era desatualizado e não estava de acordo com os avanços atuais da ciência geográfica. Mesmo com as últimas reformas feitas em 2013 através da LONCE (Ley orgánica para la mejora de la calidad educativa) a Associação de Geógrafos Espanhóis considera que os conteúdos não se alinham com a evolução cientifica da Geografia coetânea e estavam distantes dos enfoques conceituais e metodológicos das últimas décadas. Por fim, avaliam que o curriculum distanciase de países vizinhos que tratam o desenvolvimento espacial e a resolução de problemas mediante a aplicação das geotecnologias.

Desse modo, encontram-se semelhanças entre o constatado no semiárido cearense e em Badajoz, onde a geografia é baseada em um saber enciclopedista e não uma ferramenta para a 
Mendes Pontes, E.T., Silva Campos, G.., Bezerra de Carvalhoo, A. (2018): "Geotecnologias, cartografia digital e geoprocessamento aplicados ao ensino de geografia e disciplinas afins: uma experiência de extensão no semiárido cearense", GeoFocus (Artículos), no 21, p. 145-167. ISSN: 1578-5157 http://dx.doi.org/10.21138/GF.570

reflexão. Por isso, expõe-se que: a) A aprendizagem não pode estagnar-se no uso de livros e textos e tê-los como único recurso pedagógico; b) O corpo docente necessitava passar por processos de reciclagem para atualização e atuação no desenvolvimento do projeto; c) Os laboratórios não contavam com recursos tecnológicos suficientes. Os poucos computadores que existiam eram obsoletos.

Ressalta-se também a experiência da inserção das Tecnologias da Informação na Nova Zelândia. Esse processo foi iniciado na década de 1990 e aplicado de forma incipiente em projetos piloto em algumas escolas. Contudo, como no Brasil, percebe-se as semelhanças iniciais em ambos processos de implementação, isto é, falta de apoio logístico e de recursos técnicos e humanos em âmbitos local e/ou regional, conforme mostram as publicações especializadas (LOBOS, 2008).

Em 1998, o governo neozelandês tomou a iniciativa de estruturar e implantar as novas tecnologias nas escolas. Criaram o projeto Schools Cluster Programme cujo objetivo era obter infraestrutura e gerar as capacidades básicas necessárias. Foi preciso elaborar algumas medidas, tais como: conectar as escolas à internet, implementar as redes de área local (network), desenvolver um centro que produzisse e distribuísse os recursos multimídia, compra e distribuição de softwares etc.. Destarte, necessitava de forma paralela o desenvolvimento profissional do corpo docente e demais funcionários que seriam agentes ativos da implantação e uso desses meios.

A ousadia da estratégia provocou um movimento e volumosos investimentos para tal implantação, afinal era uma relevante reforma no sistema educacional. O plano do governo neozelandês se baseou em três metas: a) Criar uma liderança estratégica para controlar o processo b) Capacitar e apoiar os professores e demais profissionais envolvidos c) Entregar a infraestrutura digital às escolas que seriam as responsáveis para determinar as suas prioridades de implantação e gerenciamento. $\mathrm{O}$ andamento efetivou-se e cresceu. A comprovação foi vislumbrada em 2002 quando optaram pela integração total dos Schools Cluster Programme de maneira definitiva no curriculum escolar.

O projeto foi elaborado da seguinte forma: administração das redes, comprar de equipamentos, manutenção permanente. As funções pedagógicas consistiam em apoio, suporte, treinamentos, tutorias para professores; o programa tinha a duração inicial em 20 anos com reavaliações contínuas; suporte técnico externo dado pelas empresas fornecedoras dos softwares.

Nas primeiras avaliações periódicas da proposta alguns indicativos apresentam aspectos negativos, a saber: o treinamento externo nem sempre facilitava a participação de todos os professores; foi pleiteada formações regulares dentro da escola; havia equipamentos mas não existia estruturas lógicas e planejamentos, logo os laboratórios ficavam ociosos; o projeto não era implementado porque a liderança não estava constituída; o coordenador recebia esta atividade extra e aumentava a sua carga de trabalhos e responsabilidades. Contudo, com as devidas correções e análises ao longo do tempo, as deficiências foram superadas dentro do que se previa o projeto.

Abaixo, a Tabela 1 apresenta uma proposta de debate onde foram produzidos três eixos sinóticos onde são abordados as percepções e deteç̧ões dos problemas em cinco lugares analisados, seus agentes propugnadores e, por fim, as ações propostas e resultados obtidos e esperados. 
Mendes Pontes, E.T., Silva Campos, G.., Bezerra de Carvalhoo, A. (2018): "Geotecnologias, cartografia digital e geoprocessamento aplicados ao ensino de geografia e disciplinas afins: uma experiência de extensão no semiárido cearense", GeoFocus (Articulos), no 21, p. 145-167. ISSN: 1578-5157 http://dx.doi.org/10.21138/GF.570

\section{Tabela 1 - Eixos sinóticos de experiências com geotecnologias}

\begin{tabular}{|c|c|c|c|}
\hline $\begin{array}{l}\text { Lugares de } \\
\text { experiências }\end{array}$ & $\begin{array}{c}\text { Eixo 01 } \\
\begin{array}{l}\text { Percepção/detecção dos } \\
\text { problemas }\end{array}\end{array}$ & \begin{tabular}{|c|} 
Eixo 02 \\
$\begin{array}{c}\text { Agentes propugnadores de } \\
\text { iniciativas }\end{array}$
\end{tabular} & $\begin{array}{c}\text { Eixo 03 } \\
\text { Ações propostas e resultados } \\
\text { obtidos/esperados }\end{array}$ \\
\hline Crateús - Brasil & $\begin{array}{l}\text { - Pedagogias de ensino } \\
\text { calcadas em } \\
\text { tradicionalismos } \\
\text { - Causas estruturais: } \\
\text { laboratorial e sala de aula; } \\
\text { - Baixo nível de formação } \\
\text { profissional; } \\
\text { - Despreocupação com os } \\
\text { avanços tecnológicos; } \\
\text { - Descontextualização com } \\
\text { a globalização. }\end{array}$ & $\begin{array}{l}\text { - Iniciativa pública: através } \\
\text { dos docentes das instituições } \\
\text { de ensino. }\end{array}$ & $\begin{array}{l}\text { - Cursos voltados às geotecnologias; } \\
\text { - Formação continuada para professores da } \\
\text { rede pública; } \\
\text { - Formação extensionista para alunos do } \\
\text { Instituto Federal e comunidade externa; } \\
\text { - Publicação de trabalhos desenvolvidos } \\
\text { por alunos. } \\
\text { - Publicações técnicas apresentada por } \\
\text { professores em eventos internos e } \\
\text { externos; } \\
\text { - Aplicabilidade e replicabilidade; } \\
\text { - Melhoria de laboratórios; } \\
\text { - Melhoria do ensino-aprendizagem; } \\
\text { - Participação da sociedade; } \\
\text { - Autonomia do corpo discente. }\end{array}$ \\
\hline \begin{tabular}{|l|} 
Carolina do \\
Norte - EUA
\end{tabular} & $\begin{array}{l}\text { - Formas de ensino } \\
\text { tradicionalistas; } \\
\text { - Carência de } \\
\text { interdisciplinaridade. }\end{array}$ & $\begin{array}{l}\text { - Estado; } \\
\text { - Iniciativa privada; } \\
\text { - Iniciativa público-privada. }\end{array}$ & $\begin{array}{l}\text { - Aplicação de tecnologias nas práticas } \\
\text { pedagógicas; } \\
\text { - Inclusão cultural; } \\
\text { - Educação geográfica; } \\
\text { - Introdução da "gamefication"; } \\
\text { - Incremento da interdisciplinaridade; } \\
\text { - Autonomia do corpo discente; } \\
\text { - Desenvolvimento do projeto "21st } \\
\text { century skills". }\end{array}$ \\
\hline Bulgária & $\begin{array}{l}\text { - Problemas estruturais nas } \\
\text { escolas; } \\
\text { - Grade curricular } \\
\text { desatualizada; } \\
\text { - Formação dos docentes } \\
\text { descontextualizadas. }\end{array}$ & $\begin{array}{l}\text { - Entidades privadas. } \\
\text { - Ministério da Educação. }\end{array}$ & $\begin{array}{l}\text { - Tecnologias de mapeamento digital; } \\
\text { - Introdução das geotecnologias; } \\
\text { - Disseminação cartográfica via internet; } \\
\text { - Facilitar e popularizar a utilização de } \\
\text { material cartográfico; } \\
\text { - Salvar e manter a história nacional } \\
\text { cartográfica; } \\
\text { - Participação discente na catalogação dos } \\
\text { mapas; } \\
\text { - Programa "Cartography and GIS"; } \\
\text { - Criação do "Novo Atlas da Bulgária". }\end{array}$ \\
\hline Nova Zelândia & $\begin{array}{l}\text { - Infraestrutura atrasada; } \\
\text { - Curriculum defasado. }\end{array}$ & - Governo federal. & $\begin{array}{l}\text { - Criação de projetos nacionais para } \\
\text { desenvolvimentos de metodologias } \\
\text { voltadas às geotecnologias; } \\
\text { - Conectar escolas à internet; } \\
\text { - Criação do "Schools Cluster } \\
\text { Programme"; } \\
\text { - Capacitação profissional docente. }\end{array}$ \\
\hline $\begin{array}{l}\text { Badajoz - } \\
\text { Espanha }\end{array}$ & $\begin{array}{l}\text { - Problemas de ensino- } \\
\text { aprendizagem no } \\
\text { Fundamental e Médio: } \\
\text { modelo de ensino } \\
\text { academicista e } \\
\text { tradicionalista; } \\
\text { - Grade curricular } \\
\text { desalinhada com as } \\
\text { geotecnologias. }\end{array}$ & $\begin{array}{l}\text { - Professores da rede } \\
\text { pública; } \\
\text { - Associação de Geógrafos } \\
\text { Espanhóis. }\end{array}$ & $\begin{array}{l}\text { - Aplicação das Tecnologias da } \\
\text { Informação Geográfica; } \\
\text { - Pedagogia da Multidisciplinaridade; } \\
\text { - Contextualização metodológica para as } \\
\text { tecnologias da informação e } \\
\text { geotecnologias; } \\
\text { - Reformulação curricular Promoção da } \\
\text { interdisciplinaridade; } \\
\text { - Valorização das atividades de Tecnologia } \\
\text { e Inovação; } \\
\text { - Despertar do pensamento crítico e } \\
\text { empreendedor. }\end{array}$ \\
\hline
\end{tabular}

Fonte: elaboração dos autores, 2017. 
Mendes Pontes, E.T., Silva Campos, G.., Bezerra de Carvalhoo, A. (2018): "Geotecnologias, cartografia digital e geoprocessamento aplicados ao ensino de geografia e disciplinas afins: uma experiência de extensão no semiárido cearense”, GeoFocus (Artículos), no 21, p. 145-167. ISSN: 1578-5157 http://dx.doi.org/10.21138/GF.570

A partir da elaboração desse quadro sinótico, pode-se discutir pontos coincidentes e divergentes nas experiências relatadas em lugares de distintos processos históricos políticos, econômicos e culturais onde foram relatadas experiências com geotecnologias.

No Eixo 01 - percepção/detecção da problemática - arrolam-se as seguintes questões: a) Pedagogias descontextualizadas. b) Problemas infraestruturais. c) Formação pedagógica docente. d) Deficiência na grade curricular. O que foi relatado nas experiências traceja uma linha que independe se a realidade local está no mundo rural pobre semiárido de um país sulamericano ou de um país desenvolvido como na América do Norte ou Nova Zelândia. As características tipificadas denotam o processo de globalização, como discutido por (Santos, 2001): os lugares tornaram-se globais e todos os lugares, atualmente, são mundiais. Uma vez criadas as condições básicas tecnológicas desenvolvidas no pós-Guerra, houve uma profusa difusão das técnicas e estas, no campo das ciência Geográfica e afins, possibilitaram uma crescente capacidade de injetar na sociedade novos produtos que modificaram o cotidiano. Pode-se, então, dizer que os lugares se definem pela maior ou menor perfectibilidade dos objetos, ou seja, de sua produtividade: é nesse espectro que se irá perceber as diferenças entre as experiências supracitadas, que irão viabilizar e efetivar as resoluções apontadas no Eixo $03 \mathrm{em}$ níveis distintos

Outrossim, com a evolução dos sistemas técnicos em todas as experiencias aqui avaliadas compreendeu-se que havia a o que (Santos, 2001) chamou de convergência do momento. Mesmo não sabendo que outros atores estavam agindo, em Crateús ou na Bulgária, a formação pedagógica docente estava carecendo de contextualizações para suas devidas demandas, que tiveram em todos os relatos a problemática da grade curricular, da infraestrutura e das formações pedagógicas como vetores dessa não inserção nas geotecnologias e cartografia digital. É a unidade reconhecível dos lugares onde o que acontece tem efeito globalizado: é o lugar influindo no mundo. $\mathrm{O}$ advento da globalização modificou relações entre territórios/lugares. As redes informacionais conectaram fluxos, lugares e pessoas instantaneamente. Os recursos estão disponibilizados, mas quem os pode utilizar? Isso nos faz remeter a Trindade (2009) quando expõe que o espaço tornou-se fluido e o tempo sofreu compressão porém nem todos são fluidos. Se o despertar do século XXI é marcado pela fluidez e velocidade, há lugares e regiões ainda lentos e não que atendem às essas exigências. Portanto, as detecções aqui apresentadas no Eixo 01 coadunam-se quando dialogadas com Santos (2001) e Trindade (2009).

Essa unicidade técnica abordada compõe a capacidade de produzir coisas modernas mundialmente. E essa convergência histórica permitiu a cognoscibilidade necessária para a detecção desses problemas por partes de entes (expostos no Eixo 02) sejam estes identificados como o Estado (Escolas, Universidades, Institutos, Ministérios etc.), a iniciativa privada, as parcerias público-privadas e/ou atores sociais locais, caracterizados como docentes, alunos e cooperadores. Estes foram os vetores que, após a análise aqui disposta no Eixo 01 partiram para as ações e resultados designados no Eixo 03 .

Essas habilidades uma vez compondo ferramentas aplicáveis tornam a Geografia uma disciplina contextualizada. Concomitantemente, é gerada uma necessidade de que as grades curriculares (mencionadas no Eixo 01) sejam repensadas e requalificadas. Tais demandas compõe um ciclo virtuoso, pois o engessamento pedagógico foi amplamente apontado como fator de desequilíbrio formativo. A tecnologia por si mesmo não pode reparar tais atrasos, ela precisa de agentes capacitados que as tornem técnicas efetivas. 
Mendes Pontes, E.T., Silva Campos, G.., Bezerra de Carvalhoo, A. (2018): "Geotecnologias, cartografia digital e geoprocessamento aplicados ao ensino de geografia e disciplinas afins: uma experiência de extensão no semiárido cearense”, GeoFocus (Artículos), no 21, p. 145-167. ISSN: 1578-5157 http://dx.doi.org/10.21138/GF.570

Sequenciando o Eixo 03, vê-se que as propostas envolvem a busca por multidisciplinaridade e participação social. Nesse ponto, a experiência de Crateús demonstrou que o público interessado nessa proposta provinha de formações variadas, não restrito à Geografia, tornando, com isso, um desafio instigador para o corpo docente. Nas demais localidades ficou aparente que os desdobramentos gerados necessitam fundamentalmente de continuidades, seja na forma de criação de programas ou nas chamadas formações continuadas para docentes e/ou demais agentes que atuam nos contextos apresentados. Para isso, criar e qualificar laboratórios de informática e treinar seus corpo orientador tem sido uma resposta eficiente. A incorporação por parte das instituições de ensino dessas metodologias inovadoras é condição sine qua non para que os resultados se tornem práticas replicadoras. Dentre essas, a publicização é uma ferramenta útil, pois gera a possibilidade de reflexão e aplicação.

\section{Fundamentação teórica}

Para o propósito deste projeto de extensão, o conceito de geotecnologia coaduna-se com a noção de tecnologia, pois é a partir desta que ela passa a existir. Conforme Milton Santos (1993, p. 40), "tecnologia é o resultado de uma elaboração intelectual do homem como ele vai se comunicar com a natureza para poder modificá-la". Essa evolução é constante e o ser humano vem aprimorando seus meios tecnológicos com o passar dos tempos, notadamente a partir da Revolução Científica. Porém, a tecnologia não é apenas uma ação, mas algo pensado pelo homem para ser utilizado em seu proveito. A partir do momento em que ele a usa e ela deixa de ser algo teórico e passa a ser prático, será chamada de técnica. Desse modo, para se adotar da tecnologia em seu benefício, é preciso obter uma determinada técnica.

A técnica é a realização prática de tecnologia. E é através da realização prática de tecnologia, a técnica é que é responsável pela organização do espaço, porque o espaço vai sendo pouco a pouco povoado e habitado por técnicas [...]. (SANTOS, 1993, p. 40)

Através da técnica para utilização da tecnologia, o ser humano criou um mundo onde tudo se tornou mais rápido e prático desde a forma de se comunicar até a praticidade em se locomover, devido os avanços tecnológicos:

Nos dias atuais, a técnica e a ciência presenteiam o homem com a capacidade de acompanhar o movimento da natureza, graças aos progressos da teledetecção e de outras técnicas de apreensão dos fenômenos que ocorrem na superfície da Terra [...]. (SANTOS, 2006, p. 162)

As geotecnologias são ferramentas úteis no trabalho dos geógrafos, podendo ser utilizadas em diversas áreas, como a gestão ambiental, governamental e na educação (PONTES, 2009). Segundo Rosa (2005, p. 81), "geotecnologias são o conjunto de tecnologias para coleta, processamento, análise e oferta de informação com referência geográfica". Ela está ligada ao geoprocessamento e para que seu produto final seja construído, é preciso utilizar uma série de técnicas até que esteja pronto para utilização. Rosa e Brito exemplificam algumas técnicas e instrumentos utilizados no geoprocessamento: 
Mendes Pontes, E.T., Silva Campos, G., Bezerra de Carvalhoo, A. (2018): “Geotecnologias, cartografia digital e geoprocessamento aplicados ao ensino de geografia e disciplinas afins: uma experiência de extensão no semiárido cearense", GeoFocus (Articulos), no 21, p. 145-167. ISSN: 1578-5157 http://dx.doi.org/10.21138/GF.570

1. Técnicas para coleta de informação espacial (cartografia, sensoriamento remoto, GPS, topografia, levantamento de dados alfanuméricos); 2. Técnicas de armazenamento de informação espacial (bancos de dados -orientado a objetos, relacional, hierárquico, etc.); 3. Técnicas para tratamento e análise de informação espacial (modelagem de dados, geoestatística, aritmética lógica, funções topológicas, redes, etc.); 4. Técnicas para o uso integrado de informação espacial, como os sistemas GIS - Geographic Information Systems, LIS - Land Information Systems, AM/FM - Automated Mapping/Facilities Management, CADD - Computer - Aided Drafting and Design [...]. (ROSA e BRITO, 1996, p. 104)

Destarte, os Sistemas de Informações Geográficas (SIG) são exemplos da recente etapa das geotecnologias. Disponibilizam banco de dados, prontos a serem manuseados pelo seu usuário e para construção de dados cartográficos. São exemplos de SIG o QGIS, ArcGIS, EduSPRING etc. Sites como o do Instituto de Pesquisa e Estratégia Econômica do Ceará (IPECE), dispõem de banco de dados, nesse caso são chamados de SIG-WEB, pois só podem ser utilizados quando o usuário está conectado via internet. $\mathrm{O}$ professor/facilitador pode utilizar o SIG para trabalhar assuntos diversos, facilitando a compreensão por parte dos alunos, além de ajudar nas explicações.

Uma tecnologia que tem se popularizado é o GPS (Global Position System). Suas origens remetem à observação permanente do movimento das estrelas, passando pelo uso dos astrolábios, entre outros recursos antigos até os mais modernos, como os Sistemas Globais de Posicionamento GNSS (Global Navigation Satellite Systems): estruturas que permitem determinar em toda a Terra a posição de um objeto com uma precisão de até centímetros dependendo do recurso GNSS utilizado. Dentre outras iniciativas, existem o GPS norteamericano, o GLONASS (Globalnaya Navigatsionnaya Sputnikovaya Sistema) da antiga União Soviética, atualmente gerido pela Federação Russa, o Sistema da República Popular da China, o Beidou (nome em chinês da constelação Ursa Maior) e o Galileo, sistema de navegação por satélite da União Europeia e da Agência Espacial Europeia que se propõe a entrar em atividade total em 2020.

A primeira iniciativa foi desenvolvida e executada pelo Departamento de defesa dos Estados Unidos. Esse sistema - o GPS - é mais popular por ser o primeiro GNSS a entrar em atividade, faz uso de 24 satélites para determinar as posições no globo. Todos estes recursos desenvolvidos e utilizados servem para georreferenciar um determinado ponto, local ou espaço. O GNSS, enquanto sistema de posicionamento global, é um meio válido para se obter uma informação geográfica que colabora com a construção da base de dados. Através dos dados georreferenciados obtidos, estes podem ser usados nos SIG graças a esta integração. A difusão dos SIG e do GNSS introduziu na linguagem cotidiana a palavra georreferenciar. Em um sentido bastante abstrato significa atribuir algum tipo de coordenadas a uma determinada área, aos objetos presentes de interesse, seja natural, obras de engenharia, vértices de uma parcela etc.

Urge a necessidade de precisão ao fazer a georreferência de um determinado local, ponto ou fronteira e isto envolve não somente aspectos ou interesses geográficos, mas políticos, arqueológicos, patrimoniais, sanitários, comerciais, econômicos, dentre outros. O labor e custo estão na coleta de dados e este ônus é para que a informação possa ser contrastada e que reflita o mais próximo possível às coordenadas e nisto está a fiabilidade de um SIG. Tal característica nos sistemas de entrada de dados no SIG se baseia na qualidade dos dados inseridos e que são 
Mendes Pontes, E.T., Silva Campos, G.., Bezerra de Carvalhoo, A. (2018): "Geotecnologias, cartografia digital e geoprocessamento aplicados ao ensino de geografia e disciplinas afins: uma experiência de extensão no semiárido cearense", GeoFocus (Articulos), no 21, p. 145-167. ISSN: 1578-5157 http://dx.doi.org/10.21138/GF.570

adquiridos a partir das imagens obtidas através de satélites ou outro recurso e dos levantamentos topográficos realizados com GNSS. Tendo estas informações e após sua verificação, estas passam a ser dados e em seguida servem para alimentar os SIG. O processo da verificação é um trabalho que exige cautela e rigor já que os resultados passarão por uma austera e rígida verificação, isto é, os dados topográficos obtidos em campo, através do GPS, serão relacionados e comparados com os alcançados por satélites. A confiabilidade da informação é o resultado deste trabalho que consiste em excluir imprecisões e erros de escala, medidas ou deformações.

No âmbito da cartografia digital faz-se necessário expor que, tradicionalmente, os mapas foram representados sobre papel, embora outrora estas representações, bastante elementares, também eram feitas nas paredes das covas e/ou árvores. Dos mapas feitos nas taipas até os desenhados nas folhas houve uma mudança considerável no produto final. A cartografia sobre o papel, mesmo sendo revolucionária no passado, teve o seu devido valor técnico e científico, ainda com suas limitações. Os dados passavam por um processo de simplificação, principalmente quando se trata de extensas áreas e com isso informações e dados locais eram perdidos, além dos problemas com as escalas quando estes eram confeccionados por várias pessoas.

Com o avanço da tecnologia e a necessidade de precisão, a cartografia clássica naturalmente foi para o segundo plano, a digital se aprimora e vai substituindo o mapa tradicional em formato impresso. Isso só foi possível devido a disponibilidade de dados espaciais e das técnicas para efetuar as análises. Todas estas possibilidades abertas levaram a um célere desenvolvimento da cartografia digital, já que se podia manipular uma grande quantidade de informação a custos baixos.

Existem diferenças entre a cartografia tradicional e a atual. A primeira tem um caráter estático, isto é, as mudanças se refletiram somente na próxima versão impressa, enquanto que no formato digital o caráter é dinâmico, o usuário imediatamente terá acesso a informação editada ou ao novo dado publicado. Ainda se pode citar a evolução do conceito de mapa, na concepção tradicional o trabalho era desenvolvido sobre uma só capa (layer), enquanto que no digital o conceito se expande, resultado da combinação de várias capas, onde cada uma delas aporta um dado ou informação.

Na cartografia digital a indispensabilidade de estruturar os dados é necessária para evitar que o software fique em situação de indeterminação, pois quando isso acontece o aplicativo permanece sem recursos de ação, posto que ele não trabalha com informações genéricas e/ou ambiguidades. Assim, passa por processos rápidos de desenvolvimento. A tradicional ainda deixa marcas profundas na forma de visualizar o espaço, isto é, o mapa é confeccionado em um plano. Mas, com os avanços tecnológicos dos recursos da informática usados, a tendência é que os mapas sejam feitos a partir da tecnologia 3D (Three-dimensional computer graphics). Atualmente, encontra-se uma quantidade representativa dos mapas em 3D e os aplicativos SIG estão sendo implementados para este projeto, como o QGIS.

O Google Earth é outro modelo de geotecnologia: um software disponibilizado pelo Google cuja principal função é apresentar um modelo tridimensional da Terra, através de imagens satelitais, onde é possível localizar pontos da superfície terrestre e fazer medições de distâncias entre determinados locais, estradas e áreas, viagens virtuais entre diferentes pontos do planeta, além de servir para o estudo da paisagem e intercâmbio de informações entre os usuários. A utilização de tais imagens permite identificar e relacionar elementos naturais e sócio 
Mendes Pontes, E.T., Silva Campos, G.., Bezerra de Carvalhoo, A. (2018): "Geotecnologias, cartografia digital e geoprocessamento aplicados ao ensino de geografia e disciplinas afins: uma experiência de extensão no semiárido cearense”, GeoFocus (Artículos), no 21, p. 145-167. ISSN: 1578-5157 http://dx.doi.org/10.21138/GF.570

econômicos tais como serras, planícies, rios, bacias hidrográficas, cidades, demografia, urbanização, etc.

Diferentemente dos livros didáticos, onde as imagens observadas são escolhidas pelos autores, na utilização do Google Earth o professor tem a opção de escolher imagens de onde ele queira trabalhar com seus alunos, inclusive aquelas que mostrem paisagens conhecidas pessoalmente por eles - particularmente de locais que não constam nos livros didáticos de caráter nacional - proporcionando efetiva interação entre os alunos e os conteúdos debatidos em sala de aula (ANDRADE, MEDINA, 2007; SILVA, 2011; SILVA, F., 2015; SILVA, R., 2015).

A partir da análise e interpretação de imagens de sensoriamento remoto, os conceitos geográficos de lugar, localização, região e interação homem/natureza podem ser articulados, proporcionando o estudo de imagens da Terra e de uma localidade, bairro ou pequena rua. É inegável que a técnica aplicada à percepção e a documentação do espaço físico acontece em decorrência das pesquisas que levam o desenvolvimento e aprimoramento das tecnologias e estas passam por constante atualização e implementação de novos recursos. A aquisição de informações sobre objetos ou fenômenos não se limita à percepção primária, seja visual, auditiva ou tátil. Tecnicamente, pelas dificuldades de localização ou acesso, é necessário colher estas informações e gerenciá-las de forma remota. Os fenômenos ou espaços a serem observados, na maior parte das vezes, são de dimensões maiores e para observá-los e adquirir os dados necessitam de recursos técnicos para este empreendimento. De forma elementar considera-se que o sensoriamento remoto é a tecnologia que permite coletar informações acerca de objetos ou fenômenos com a assistência de sensores sem que haja contato físico entre eles.

O espaço físico está e vive em contínua variação e isso ocorre devido a ação humana e a evolução natural do ecossistema. Portanto para compreender estas mudanças é necessário fazer observações com um conjunto de escalas espaciais e temporais. Um dos recursos mais utilizados para observação da Terra de forma econômica é através de satélites, principalmente em países de grandes extensões territoriais, como o Brasil. Por meio das imagens obtidas por satélites se pode obter uma observação de grandes extensões em uma só imagem e em segundo lugar, estas imagens podem ser obtidas em diversos períodos de um tempo estabelecido, e podese empreender observações desde um espaço regional, local, continental ou até mesmo de um quarteirão. Ainda que as imagens obtidas por satélites sejam as mais utilizadas, existem outras formas de adquiri-las e por isso são classificadas como imagens de laboratório ou campo, de aeronaves e as orbitais (satélites).

Albuquerque (2011) afirma que as metodologias de ensino devem permanecer em contínua construção pelos professores e teóricos da educação formada na relação entre seleção e abordagem dos conteúdos, fundamentação teórica, técnicas de ensino propostas no âmbito da pedagogia e as práticas de sala de aula, assim como as demais disciplinas escolares. Por isso, Cavalcante ressalta:

No ensino de Geografia, as geotecnologias têm como objetivo desenvolver a capacidade de compreensão do espaço geográfico dos alunos, além de colocar a disposição deles, o conhecimento destas novas tecnologias, para que possam contribuir para o desenvolvimento da ciência[...]. (CAVALCANTE, 2011, p. 39) 
Mendes Pontes, E.T., Silva Campos, G.., Bezerra de Carvalhoo, A. (2018): "Geotecnologias, cartografia digital e geoprocessamento aplicados ao ensino de geografia e disciplinas afins: uma experiência de extensão no semiárido cearense”, GeoFocus (Artículos), no 21, p. 145-167. ISSN: 1578-5157 http://dx.doi.org/10.21138/GF.570

O aprendizado através das geotecnologias abrange várias áreas do conhecimento, desde o técnico, para o manuseio das ferramentas tecnológicas (o que é fundamental para se sobressair em um mundo cada vez mais informatizado), até as competências específicas. A utilização de geotecnologias nas aulas traz imagens do cotidiano vivido pelos alunos e pode promover interesse no aprendizado dos conteúdos abordados, desse modo, eleva o nível de rendimento no aspecto ensino-aprendizagem. Conforme Saussen e Machado:

Salienta que o uso de imagens de satélite no estudo da geografia em sala de aula contribui para uma didática mais significativa na educação escolar, porque esse recurso promove a realização de aulas mais diversificadas e atrativas, nas quais o aluno poderá se sentir mais motivado, pois é possível estudar o espaço geográfico da própria região com imagens de satélite que permitem identificar o uso e cobertura do solo, o desenho urbano, os impactos ambientais, entre outros aspectos [...]. (SAUSSEN; MACHADO, 2004, p. 1486)

Apesar do fácil acesso e da disponibilização de algumas geotecnologias encontradas gratuitamente na internet, há professores não utilizam desses meios nas suas aulas. Alguns fatores que contribuem para que SIG e softwares não sejam frequentemente utilizados nas escolas é a carência de preparação continuada para professores, que não a tiveram adequadamente durante sua formação e assim pudessem manusear e utilizar as geotecnologias na docência.

Outro problema comum é a falta de estrutura de algumas escolas, principalmente as de ensino público, que não possuem computadores suficientes e/ou não estão em condições de uso por estarem obsoletos ou o laboratório de informática não suporta uma turma completa de alunos ou debilidades do sinal de internet, ausência de laboratório de informática etc.

A utilização da internet dispõe de mudanças no arcabouço político e pedagógico das instituições educacionais, promovendo ajustes e apoiando os docentes nessa tarefa. É preciso problematizar a aplicabilidade do modelo de avaliação dos alunos, fazer a avaliação da produção realizada pelos alunos com o auxílio dos recursos que a pesquisa através da Internet possibilita a eles, faz com que o professor tenha estado atento a novas perspectivas que que estavam em questão, para que possa compreender as conclusões a que chegaram a novos parâmetros e modelos de aplicação desses recursos. (PAIVA, 2015, p. 22)

Apesar do computador já ser um objeto comumente acessível e a internet fazer parte do cotidiano, há escolas que não possuem laboratório de informática e internet, dificultando a utilização das geotecnologias no E-P-E.

Porém esses enclaves não impedem que o professor traga para sala de aula imagens de satélite, mapas digitais criados a partir de SIG, dentre outros materiais retirados das tecnologias geográficas e utilizadas de forma impressa ou outra maneira a ser apresentada aos alunos, tornando as aulas de Geografia providas de detalhamento de conteúdos abdicando da memorização de informações que tornam a disciplina monótona e desinteressante, recordando que os Parâmetros Curriculares Nacionais (PCN's) incentivam a inserção de tecnologias no ambiente escolar (CARVALHO, 2016). 
Mendes Pontes, E.T., Silva Campos, G.., Bezerra de Carvalhoo, A. (2018): "Geotecnologias, cartografia digital e geoprocessamento aplicados ao ensino de geografia e disciplinas afins: uma experiência de extensão no semiárido cearense", GeoFocus (Articulos), no 21, p. 145-167. ISSN: 1578-5157 http://dx.doi.org/10.21138/GF.570

\section{Metodologia (processos, etapas, técnicas, materiais e métodos)}

O projeto em tela foi planejado a partir da proposta do edital PAPEX/PROEXT, conforme relatado e objetivava durante seu período de execução (06 meses) realizar um curso de extensão abordando geotecnologias, geoprocessamento e cartografia digital com a participação da coordenação e de três bolsistas. Para que os objetivos fossem alcançados, foram realizados os seguintes procedimentos:

- Divulgação do curso: no âmbito do IFCE, redes sociais, escolas da rede pública do município e adjacências e em organizações não-governamentais.

- Após a divulgação, foram feitas as inscrições para as 27 vagas ofertadas, por ordem de chegada e que contemplassem alguns pré-requisitos, como ter concluído o ensino médio e disponibilidade para frequentar o curso noturno.

- O projeto previa o pagamento de bolsas de extensão aos discentes regularmente matriculados no IFCE no valor de R \$ 400,00 mensais, com vigência de 06 (seis) meses. Sendo assim, foram selecionados mediante entrevista e feitura de carta de intensão os três alunos bolsistas.

- De junho a outubro realizaram-se encontros semanais presenciais no Laboratório de Informática do IFCE - campus Crateús, com os 27 (vinte e sete) matriculados, às quartas-feiras, de 18:30 às 21:30h.

- Durante o curso foi disponibilização material didático de estudo (de forma on-line) e cada cursista recebeu um pen drive contendo apostilas, artigos, dissertações, monografias, teses e assuntos trabalhados nas aulas;

- Cada cursista teve a sua disposição 01 (um) computador com acesso à internet, onde pude conhecer e praticar os atributos de cada geotecnologia apresentada;

- Os cursistas tiveram acesso aos softwares, SIG-web e geotecnologias de código aberto, como o QGIS, Google Earth, Google Street View, Gephi, realidade virtual, GPS, sites do Instituto de Pesquisa e Estratégia Econômica do Ceará (IPECE), Instituto Brasileiro de Geografia e Estatística (IBGE), Instituto Nacional de Pesquisas Espaciais (INPE) além de demais sites para aprendizado dos conteúdos: http://www.viewsoftheworld.net/; http://geografia-digital.blogspot.com.br/; http://wikimapia.org/; http://geografiavisual.com.br/; https://www.flightradar24.com; http://www.dgi.inpe.br/; http:/www.apac.pe.gov.br/ além de sites conhecidos como gamification, onde se traz jogos para o processo de aprendizado, aliando entretenimento com conhecimento, tais como: http://www.jogos-geograficos.com/; http://www.juegos-geograficos.com/; http://thetruesize.com; https://www.geocaching.com, etc.

- O curso proporcionou a utilização de técnicas para coleta, armazenamento, tratamento e uso de informação espacial através dos acessos citados, intercalando momentos de repasse de conteúdo e primordialmente atividades laboratoriais.

- Além do aprendizado com práticas pedagógicas, os cursistas tiveram a oportunidade de aprender a compor mapas utilizando a ferramenta QGIS. Existem uma variedade de softwares desenvolvidos e empregados em geotecnologias. Esta multiplicidade leva a 
Mendes Pontes, E.T., Silva Campos, G.., Bezerra de Carvalhoo, A. (2018): "Geotecnologias, cartografia digital e geoprocessamento aplicados ao ensino de geografia e disciplinas afins: uma experiência de extensão no semiárido cearense", GeoFocus (Artículos), no 21, p. 145-167. ISSN: 1578-5157 http://dx.doi.org/10.21138/GF.570

elaboração de alguns critérios adotados para escolher o aplicativo que melhor se amolda às necessidades desta ação. Atualmente, encontram-se softwares comercializados de alta qualidade e o tê-los implica em custos ao adquirir a licença de uso e suporte técnico. Estes são conhecidos como SIG comerciais.

Por outro lado, existem as iniciativas colaborativas desenvolvidas através da licença Open Source onde entidades, como a Open GeoSpatial Consortium (OSGEO) e o projeto GNU (acrônimo recursivo para GNU Is Not Unix) de software livre dão aval a vários projetos e estão disponíveis para download sem custo algum.

Entre os existentes adota-se o QGIS, que aporta os recursos necessários de um SIG e está no mesmo nível de qualidade que um software comercial. QGIS está desenvolvido para plataformas GNU/Linux, Unix, Mac OS, Microsoft Windows e Android. Esta versatilidade multiplataforma do programa é útil pois está disponível nos diversos sistemas operacionais de computadores nos campi, para uso doméstico e smartphones dos professores, alunos e colaboradores. Este software aberto é disponibilizado com permissão de uso, cópia e distribuição na sua forma original ou com modificações.

Vale assinalar que existe uma iniciativa de suporte de usuários que se integram por meio de listas de discussões e redes sociais onde através de um sistema colaborativo os membros intercambiam experiências, tutorias e tutoriais, vídeos de ajuda How to?, entre outros recursos de suportes. Isso faz com que o QGIS seja o software SIG mais usado e atende as necessidades deste projeto.

Também houve manuseio e práticas com GPS (Figura 2), disponíveis no campus Crateús, onde os alunos puderam compreender essa ferramenta e alguns de seus múltiplos usos.

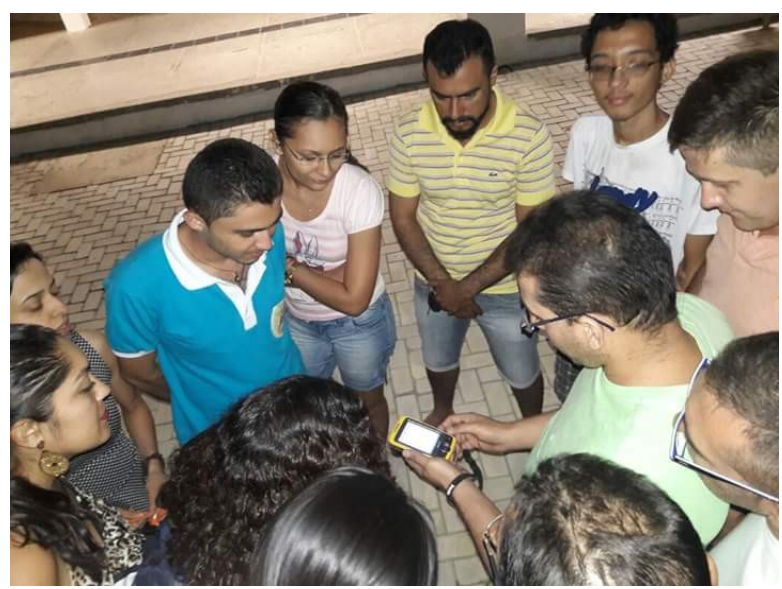

Figura 2: atividade prática com o GPS

Fonte: Caio Sousa, 2016.

- Em relação aos aparelhos de telefonia móvel e similares portáteis, uma tendência tecnológica viável e de baixo custo é através de Mobile Learning (M-Leaning), isto é, professores e alunos criam ambientes de aprendizagem à distância, reduzindo o tempo e facilitando a atualização de conteúdos. Conforme a Pesquisa Nacional por Amostra de Domicílios (PNAD), 66,4 \% dos estudantes do Ceará possuem telefonia móvel para uso pessoal. (BRASIL, 2015). Nesta ação extensionista foi utilizado M-Learning para temas como o 
Mendes Pontes, E.T., Silva Campos, G., Bezerra de Carvalhoo, A. (2018): “Geotecnologias, cartografia digital e geoprocessamento aplicados ao ensino de geografia e disciplinas afins: uma experiência de extensão no semiárido cearense", GeoFocus (Articulos), no 21, p. 145-167. ISSN: 1578-5157 http://dx.doi.org/10.21138/GF.570

geochaching, coordenadas cartográficas, etc. Nessa ambiência, usou-se recursos de realidade virtual, uma tecnologia que traz impacto visual vinculado a temas variados, no caso em questão, relacionados às geotecnologias.

- O aprendizado gerado fez com que os cursistas, de posse, uso e acesso a banco de dados, pudessem estar capacitados para composição de produtos finais (mapas, imagens etc), aplicação em sala de aula, trabalhos de conclusão de curso e demais finalidades que as demandas individuais ensejassem;

- Conforme o calendário pré-divulgado, após o término dos conteúdos programáticos, os cursistas poderiam voltar ao laboratório para exercer e praticar as técnicas aprendidas com o apoio do professor e dos bolsistas, tornando o campus cada vez mais como um equipamento de uso da comunidade, não restrito aos seus alunos e servidores.

- Ao final do curso, houve a divulgação dos resultados nas mídias sociais, valorizando as experiências. Ademais, foi organizada uma exposição com banners dos resultados alcançados pelos alunos.

O curso teve carga horária de 120 horas, conforme detalhamento no Tabela 2.

Tabela 2 - Carga horária e detalhamento da formação

\begin{tabular}{|c|l|}
\hline Carga horária & \multicolumn{1}{|c|}{ Etapas } \\
\hline 36 horas & • Apresentação da estrutura do projeto \\
& • Estudos teóricos \\
& • Uso e aplicação das geotecnologias \\
& - Relação didático-pedagógica \\
\hline 36 horas & Práticas de ensino - aplicações em sala de aula \\
\hline 24 horas & Elaboração dos produtos finais \\
\hline 20 horas & $\begin{array}{l}\text { Práticas laboratoriais extras para consolidação do conteúdo } \\
\text { repassado }\end{array}$ \\
\hline 4 horas & Exposição dos banners \\
\hline TOTAL 120 horas & \\
\hline 12 h semanais & Práticas laboratoriais exclusivamente com os bolsistas \\
\hline
\end{tabular}
Fonte: os autores, 2017 
Mendes Pontes, E.T., Silva Campos, G.., Bezerra de Carvalhoo, A. (2018): "Geotecnologias, cartografia digital e geoprocessamento aplicados ao ensino de geografia e disciplinas afins: uma experiência de extensão no semiárido cearense", GeoFocus (Articulos), no 21, p. 145-167. ISSN: 1578-5157 http://dx.doi.org/10.21138/GF.570

Na Tabela 3, consta o conteúdo programático elaborado para o curso.

Tabela 3 - Conteúdo programático

\begin{tabular}{|c|l|}
\hline Aulas & \multicolumn{1}{c|}{ Conteúdo programático } \\
\hline 01 & $\begin{array}{l}\text { Apresentação da estrutura do curso e } \\
\text { Nivelamento da turma }\end{array}$ \\
\hline 02 & $\begin{array}{l}\text { Introdução as geotecnologias } \\
\text { Técnicas de captação de imagens }\end{array}$ \\
\hline 03 & $\begin{array}{l}\text { SIG - sistema de informações geográficas } \\
\text { Sensoriamento remoto } \\
\text { Coordenadas geográficas e Aerofotogrametria }\end{array}$ \\
\hline 04 & GPS - conceito e prática \\
\hline 05 & $\begin{array}{l}\text { Google Earth } \\
\text { Gamification }\end{array}$ \\
\hline 06 & $\begin{array}{l}\text { Google mapas e Google street view } \\
\text { Realidade virtual }\end{array}$ \\
\hline 07 & Banco de imagens e banco de dados \\
\hline 08 & Leitura e interpretação de cartas e mapas digitais \\
\hline 09 & $\begin{array}{l}\text { Ferramentas cartográficas digitais } \\
\text { Gephi }\end{array}$ \\
\hline 10 & Atlas digital \\
\hline 11 & QGIS \\
\hline 12 & QGIS \\
\hline
\end{tabular}

Fonte: os autores, 2017.

O conteúdo previsto teve nível satisfatório de compreensão por parte dos cursistas, sendo dado em sua íntegra. A proposta de avaliação foi prática (em sala de aula) e elaboração de produtos finais (mapas/imagens). O desempenho dos cursistas visou ao mapeamento do seu desenvolvimento profissional e contínuo durante a formação, procurando detectar os avanços e as necessidades de intervenções. Esse processo de avaliação considerou a sua frequência e participação nas sessões presenciais coletivas, além do material que produziram e os registros das atividades. A certificação do cursista foi mediante os seguintes critérios: frequência mínima de $75 \%$; realização e registro das atividades propostas e desenvolvidas em sala de aula.

\section{Resultados e discussões}

Para um campus inserido em pleno semiárido nordestino, a presente proposta de extensão traz em seu bojo alguns aspectos a serem analisados e que doravante serão designados como avanços e desafios encontrados na aplicação e em seus desdobramentos e aplicabilidade.

A) Acesso regular à internet. Os apoios necessários para a implementação e expansão desta iniciativa pressupõem, em situação de normalidade, alguns recursos que não podem ser dispensados com a finalidade da plena realização. Os desafios encontrados indicam que para viabilizá-lo é necessário superar algumas debilidades alheias a esta proposta, como por exemplo, uma rede estruturada que possibilita todo tipo de conexão em network, seja intranet ou internet em velocidade aceitável, através de aparelhos celulares, tablets e computadores. Sem essa conectividade a implantação das iniciativas estará comprometida.

B) Laboratórios de informática. Ocorrem distintas situações quanto a esses espaços, tais como: i) existem, porém são não aparelhados (computadores não funcionam ou 


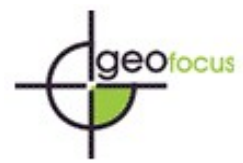

Mendes Pontes, E.T., Silva Campos, G.., Bezerra de Carvalhoo, A. (2018): "Geotecnologias, cartografia digital e geoprocessamento aplicados ao ensino de geografia e disciplinas afins: uma experiência de extensão no semiárido cearense", GeoFocus (Articulos), no 21, p. 145-167. ISSN: 1578-5157 http://dx.doi.org/10.21138/GF.570

possuem configurações obsoletas) e em quantidade que não atende à demanda da escola/instituto; ii) Existem, são razoavelmente equipados, porém subutilizados por falta de capacitação dos profissionais. Esse subitem gera outra problemática: por que não são capacitados? Falta de interesse ou de acesso à formação continuada? A possibilidade de cursos como este busca suprir as duas perguntas citadas, pois dinamiza o espaço (gerando interesse) e capacita os cursistas. Além disso, inserir alunos/professores do sertão cearense em um processo de know-how globalizado no que se refere às geotecnologias é concretizar sua inclusão digital; iii) Existem, são equipados e possuem material humano capacitado, logo necessitam, entre outras, de atividades de extensão. No caso específico do campus IFCE Crateús, o laboratório de informática atendeu a todas demandas do curso, caracterizando-o com um dos pontos relevantes para o projeto.

C) Replicar o curso. O modelo do projeto pedagógico desta atividade de extensão é ser replicado, tanto no campus onde houve a primeira experiência, como em demais espaços, por isso a necessidade de publicação e divulgação em meios científicos. Essa possibilidade é factível baseada nos seguintes argumentos: o nível de evasão do curso foi irrelevante, portanto, leva a concluir o interesse pela proposta; os resultados obtidos na atividade avaliativa que culminaram com uma exposição em banners (Figura 3) de seus trabalhos lograram analisar a inserção dos conteúdos repassados com as reais necessidades dos cursistas, concretizando uma das ênfases da extensão que é unir a comunidade externa com o Instituto; a coordenação do curso considerou que os produtos finais estavam com nota acima da média estabelecida $(7,0)$ pelo IFCE - Crateús, revelando um aprendizado qualitativamente aprovado; os conteúdos programáticos foram entregues aos cursistas em pen drive, favorecendo com que estes sejam multiplicadores das geotecnologias em seus múltiplos campos de atuação; a replicação do aprendizado, a médio e longo prazo, proporcionará eficiência no uso dos laboratórios de informática nas escolas da região, assim como na interação tecnológica entre alunos e professores para conteúdo das disciplinas de geografia e ciências afins.

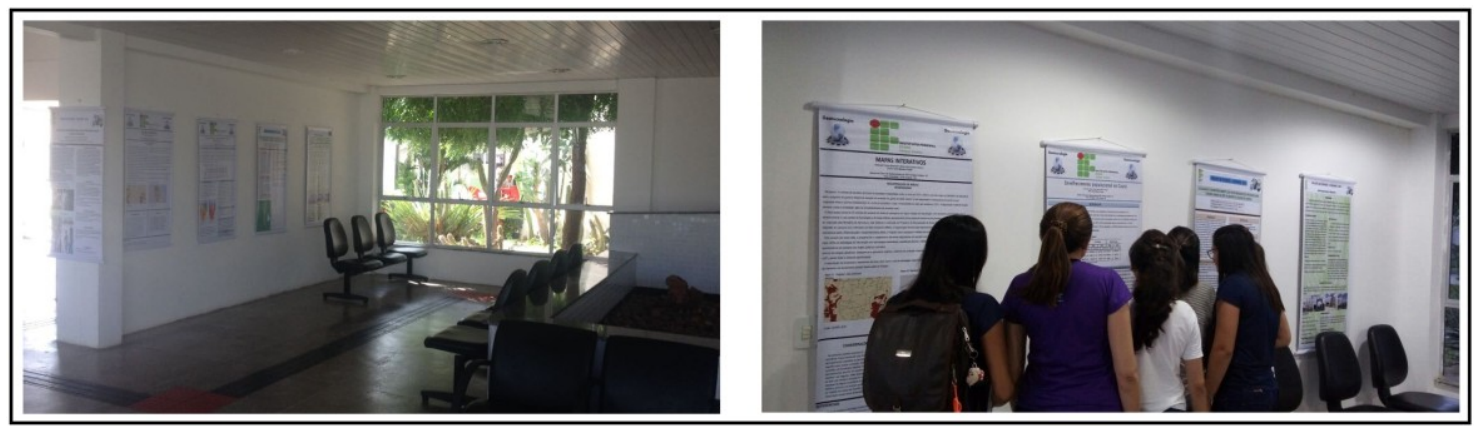

Figura 3 - Exposição de banners dos trabalhos finais do curso de extensão no IFCECrateús

Fonte: Antônio Adílio Silva, 2017

A exposição dos banners logrou estabelecer uma via de comunicação entre o projeto extensionista com a comunidade acadêmica do campus e a público externo.

D) A possibilidade do acompanhamento in loco dos facilitadores de um curso de extensão em geotecnologias nas respectivas escolas dos cursistas para aplicação do conteúdo tende a ser um diferencial nesse processo de formação. Uma sugestão prática é oportunizar ao cursista em sua escola alguma ferramenta de acesso às geotecnologias para o ambiente que pleiteia implementar em sua proposta pedagógica a viabilidade das tecnologias, seja em um 
Mendes Pontes, E.T., Silva Campos, G.., Bezerra de Carvalhoo, A. (2018): "Geotecnologias, cartografia digital e geoprocessamento aplicados ao ensino de geografia e disciplinas afins: uma experiência de extensão no semiárido cearense”, GeoFocus (Articulos), no 21, p. 145-167. ISSN: 1578-5157 http://dx.doi.org/10.21138/GF.570

auditório ou na sala de aula. Nessas ocasiões, é necessário um aparato mínimo (notebook e projeção) que maximize para a plateia os conteúdos ministrados. Uma metodologia eficaz e inclusiva é viabilizar com os alunos o potencial que seus celulares, tablets e smartphones possuem, fazendo interação com aplicativos on line (citados na Metodologia).

Dentre as iniciativas existentes que servem como recursos para promover a aprendizagem através deste viés, cita-se o Geocaching, um aplicativo de gamification que consiste em conjugar espaço, coisas e utensílios. Este recurso é prático e de fácil intuição operacional. A descarga é feita através da página web do aplicativo e está disponível para computadores e smarthphones em todas as plataformas. Em Crateús, houve a iniciativa de implantar um cache piloto, processo acompanhado pela coordenação do curso onde foram trabalhados princípios básicos de coordenadas geográficas, cartografia, uso do GPS e o manuseio do aplicativo Geocaching. A atividade foi desenvolvida em duas etapas. Na primeira, houve a apresentação da proposta e dos fundamentos teóricos e logísticos, depois passou-se para o espaço externo onde o entendimento adquirido em classe se transformou em práticas.

O objetivo principal é encontrar um determinado objeto (caching) através das coordenadas geográficas escondidas em um local demarcado. A atividade utiliza os diversos interesses, desde a simples curiosidade em conhecer novos lugares, a emoção que é a alavanca motivadora para o exercício até o conhecimento e aplicação de fundamentos da geolocalização usando princípios de espacialidade como latitude, longitude e o uso de geotecnologia, GPS, leitura e interpretação de mapas, análises geofísicas, práticas ecológicas, conservação ambiental etc. $\mathrm{O}$ uso deste jogo ou de outro - a gamification - dentro dos processos de aprendizagem da Geografia serve como tática que estimula e proporciona o interesse dos educandos através da manipulação e aplicação de conceitos geográficos e a estreita relação com os instrumentos cartográficos. Há a combinação de uma aprendizagem prazerosa através de aplicação e práticas extraclasses.

E) Destaca-se o auxílio financeiro dado pelo edital PAPEX/PROEXT do IFCE que financiou este projeto, possibilitando a presença de 3 (três) bolsistas durante os 06 (seis) meses se efetivação. Essa particularidade trouxe um aporte de dinamicidade para a execução do curso e um ganho de aprendizado para os escolhidos ao receber a bolsa (estudantes do campus IFCE Crateús, selecionados após processo seletivo simplificado), oportunizando-lhes prática laboratorial juntos aos cursistas e orientação individual por parte da coordenação do projeto. Os bolsistas estiveram por todo o período do curso auxiliando os cursistas, propiciando maior agilidade na disseminação dos saberes.

F) O projeto também se deparou com desafios. O primeiro deles foi percebido durante o nivelamento: enquanto alguns podiam praticar em casa os conteúdos repassados, outros não tinham as mesmas condições, seja por falta de equipamentos ou ausência/debilidade de sinal de internet, algo relativamente trivial no sertão semiárido cearense. Tal situação demandou tempo de aulas expositivas e treinamentos individuais no laboratório. Contudo, dado o esforço dos cursistas e bolsistas, não deteve o avanço no aprendizado. Essa realidade poderá inferir em similares situações quando das replicações do curso em lugares cujas carências sociais e estruturais sejam semelhantes.

G) Outro desafio percebido se correlaciona com a rejeição, a priori, que se tem nas relações das geotecnologias com as tradicionais práticas pedagógicas voltadas unicamente para utilização do livro didático. As razões encontradas para tal rejeição recaem no dinamismo que as 
Mendes Pontes, E.T., Silva Campos, G.., Bezerra de Carvalhoo, A. (2018): "Geotecnologias, cartografia digital e geoprocessamento aplicados ao ensino de geografia e disciplinas afins: uma experiência de extensão no semiárido cearense”, GeoFocus (Artículos), no 21, p. 145-167. ISSN: 1578-5157 http://dx.doi.org/10.21138/GF.570

novas tecnologias possuem, portanto, gerando a necessidade de sair das comodidades e buscar formação. Por outro lado, aos interessados falta acesso à formação continuada nessa área do conhecimento, reforçando a necessidade da divulgação desta experiência extensionista.

\section{Conclusões}

A introdução de práticas pedagógicas e ações extensionistas voltadas às geotecnologias e temas afins, têm produzido efeitos de inclusão digital e provocado dinamização e expansão do aprendizado através do acesso a uma gama de possibilidades advindas dessas ferramentas, resultados atestados não somente na experiência aqui analisada, como em publicações encontradas na literatura especializada.

Com o passar do tempo, as formas até então conhecidas e usadas nas instituições educacionais passaram por um processo transicional, pois estes não correspondiam às necessidades emergentes que surgiam. As releituras e mudanças nas práticas educacionais, desde os fundamentos didáticos até os pedagógicos exigiam novas respostas que renovassem ou mesmo rompessem com o ensino tradicional, isso se deu devido às transformações socioeconômicas e espaciais dos últimos anos que estimulavam um olhar crítico que esteve ausente. A Geografia, não diferente das demais, teve que reavaliar o método clássico, por vezes monótono e enfadonho. Os resultados finais estavam comprometidos devido a perca do feeling, e quando esta intuição se escasseia o produto final, neste caso a aprendizagem, alcança rendimentos abaixo do programado. Os desafios estavam lançados e a necessidade de gerar e construir novos paradigmas e recursos para o uso em Ensino-Pesquisa-Extensão eram cogentes. Entre as várias iniciativas implementadas, por exemplo, a renovação dos livros-textos e a recapacitação dos professores não respondia às necessidades e urgiam correções. Atualmente, esta tarefa segue na lista de prioridades.

A expansão dos recursos utilizados em sala de aula tal como imagens, mapas, plantas urbanas entre outros seguem sem responder na totalidade as necessidades da compreensão da Geografia enquanto uma disciplina espacial, onde o ser humano vive e se relaciona com o meio. Isso leva a repensar os fundamentos metodológicos. A aprendizagem evoca e passa a propor ensaios de deslocamentos onde o aluno experimenta e compreende a disciplina como uma ferramenta de compreensão do contexto social dentro do espaço geográfico.

Ao estabelecer uma análise da experiência aqui trabalhada com outras internacionais, observam-se pontos em comum e divergentes. No caso da Bulgária, as publicações especializadas mostram que a introdução da cartografia digital e do geoprocessamento nas escolas por conta de uma política do Ministério da Educação e Ciência desse país constatou aquilo que observou-se no caso em tela, a saber: a) a desqualificação de professores de geografia e disciplinas afins em suas habilidades referentes às geotecnologias; b) a necessidade de políticas públicas para capacitação desses profissionais através de formação continuada; c) introdução das geotecnologias no currículo escolar. Como aplicação direta, o Ministério da Educação búlgaro tem incentivado e investido na Escola Nacional de Cartografia e SIG, promovido mobilidade docente para intercâmbio e expansão do conhecimento e aprimoramento da inter interdisciplinaridade como forma de expandir os conteúdos. Tais conclusões do caso búlgaro reforçam a necessidade da expansão das atividades extensionistas e do investimento do Estado para solucionar essas lacunas formativas em instituições de ensino no território brasileiro. 
Mendes Pontes, E.T., Silva Campos, G.., Bezerra de Carvalhoo, A. (2018): "Geotecnologias, cartografia digital e geoprocessamento aplicados ao ensino de geografia e disciplinas afins: uma experiência de extensão no semiárido cearense”, GeoFocus (Artículos), no 21, p. 145-167. ISSN: 1578-5157 http://dx.doi.org/10.21138/GF.570

Analisando as experiências na Nova Zelândia, nota-se que o êxito se efetiva somente através de políticas e responsabilidades governamentais. A inovação do processo e a aplicação das novas tecnologias tem que ser acompanhadas de uma preparação adequada dirigida aos docentes. A obtenção de êxito efetivou-se quando a atenção e a formação do professorado e demais profissionais envolvidos foi priorizada. Afinal, não basta ter um parque tecnológico repleto de computadores e instrumentos para as atividades se os recursos humanos são/estão debilitados.

As aplicações das geotecnologias se deram no advento das implementações e uso da tecnologia da informação aplicada. Atualmente, a relação com o espaço é planteada de outro modo: o recurso utilizado para as aulas de humanas era restrito ao aspecto livresco e poucas instituições tinham recursos cartográficos. Contudo, ainda persistem entidades que fazem desse o único recurso, por inabilidade pedagógica, cultural e/ou financeira. Se por um lado tem-se um sistema educacional que funciona a partir de recursos mínimos, obsoletos e clássicos, por outro encontra-se um universo sem fronteiras que brinda incontáveis experiências, onde o mesmo aluno que frequenta um sistema educativo tradicional, com desinteresse e tédio passa a conhecer uma outra realidade envolvente na qual vivencia uma outra forma de perceber e relacionar com o mundo. Este estudo feito indica claramente que existe um descompasso entre a informação acadêmica e a sua aplicação. Os modernos recursos existentes já são usados e experimentados por crianças e adolescentes desde a tenra idade, que é facilitada pelo acesso a web através de videogames, smartphones entre outros. A virtual reality está presente por todos os lados e a comprometedora ausência de sincronia entre o ensino-aprendizagem e a vida cotidiana tem que ser superado.

Diversificar, dinamizar, propor novas metodologias e obter resultados qualitativos compõem esta proposta de projeto de extensão que per se deve se auto atualizar à medida que em seu bojo encerra tal característica, corrigindo deficiências e ficar antenado às demandas globais com reflexos locais, como no caso específico aqui analisado no sertão cearense.

\section{Referências bibliográficas}

Andrade, A., \& Medina, S. (2007). O uso de imagens de satélite do Google Earth como recurso didático para o ensino de projeções de coberturas. Apresentado em VII International Conference on Graphics Engineering for Arts and Design, Curitiba, Paraná. Recuperado de http://www.exatas.ufpr.br/portal/docs_degraf/artigos_graphica/OUSODEIMAGENS.pdf.

Bandrova, T. (2005). Training school on cartography and GIS in Bulgaria. Consultado em 12 de agosto de 2017., de http://lazarus.elte.hu/cet/madrid-2005/bandrova.pdf.

Bandrova, T. (2010). Bulgarian Cartography: from Paper to Virtual Reality. Apresentado em 3rd International Conference on Cartography \& GIS, Nessebar, Bulgaria. Recuperado de https://cartography-gis.com/html_css/01themes.html. Consultado em 12 de agosto de 2017.

Carvalho, A. (2016). Geotecnologias aplicadas ao ensino de geografia na escola José Aloísio na cidade de Ipueiras - CE (Monografia de graduação em Geografia). Universidade Estadual Vale do Acaraú, Sobral.

Cavalcante, M. (2011). As Geotecnologias no ensino da Geografia no século XXI. Saber Acadêmico, 12, p.39.

De la Riva, J., Ibarra, P., Montorio, R. \& Rodrigues, M. (2015). Análisis espacial y representación geográfica: innovación y aplicación. En: XXIV Congreso de la Asociación de 


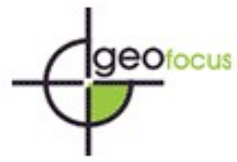

Mendes Pontes, E.T., Silva Campos, G., Bezerra de Carvalhoo, A. (2018): “Geotecnologias, cartografia digital e geoprocessamento aplicados ao ensino de geografia e disciplinas afins: uma experiência de extensão no semiárido cearense", GeoFocus (Articulos), no 21, p. 145-167. ISSN: 1578-5157 http://dx.doi.org/10.21138/GF.570

Geógrafos Españoles. Zaragoza: Departamento de Geografía y Ordenación del Territorio, Universidad de Zaragoza, pp.1301-1310. Recuperado de: http://congresoage.unizar.es/[Consultado en 10 Jun. 2017].

Fonseca, L. (2004). Por uma economia política das geotecnologías. Revista Electrónica de Geografia y Ciencias Sociales, VIII(170). Retrieved from http://www.ub.edu/geocrit/sn/sn-17052.htm

Gómez, M. (2013). GPS and Geography: Using Technology to Apply Geography with Middle Grade Students. Social Studies Research \& Practice. [ebook] Alabama, pp.43-54. Available at: http://www.socstrpr.org/wp-content/uploads/2013/07/3-Final-Summer-2013-MS06483Gomez.pdf. Consultado em 12 agosto 2017.

Machado, C., \& Saussen, T. (2004). A Geografia na sala de aula: informática, sensoriamento remoto e sistemas de informações geográficas - recursos didáticos para o estudo do espaço geográfico. Apresentado em $4^{\mathrm{a}}$ Jornada de Educação em Sensoriamento Remoto no Âmbito do Mercosul, São Leopoldo. Recuperado de http://bibdigital.sid.inpe.br/rep/ltid.inpe.br/sbsr/2004/11.19.21.46.

Paiva, I. (2015). A utilização das Geotecnologias como recurso didático no ensinoaprendizagem de Geografia (Trabalho de Conclusão de Curso (Graduação)). Universidade Vale do Acaraú, Sobral.

Pesquisa Nacional por Amostra de Domicílio. (2015). Instituto Brasileiro de Geografia e Estatística - IBGE. Recuperado 16 de março de 2017, de http://www.ibge.gov.br/estadosat/temas.php?sigla=ce\&tema=pnad_internet_celular_2015.

Pinto, F. C. F.; Garcia, V. C. \& Letichevsky, A. C. (2006). Pesquisa Nacional Qualidade na Educação: a escola pública na opinião dos pais. Ensaio: Avaliação e Políticas Públicas em Educação, 14(53), 527-541. https://dx.doi.org/10.1590/S0104-40362006000400008.

Pontes, E., (2009). Uso do geoprocessamento no diagnóstico e espacialização dos recursos hídricos do município de Afogados da Ingazeira - PE (Monografia de Pós-graduação). Universidade Estadual do Ceará, Fortaleza.

Lobos, M. Q. (2008). Análisis Comparado de Experiencias de Introducción de las TIC en el Aula. El Rol del Coordinador Tecnológico y su Impacto en el Éxito de las Políticas Públicas. REICE. Revista Iberoamericana sobre Calidad, Eficacia y Cambio en Educación, 6(4), pp. 149164.

http://www.rinace.net/reice/numeros/arts/vol6num4/art8.pdf. Consultado em 12 de agosto de 2017.

Rosa, R. (2011). Geotecnologias na Geografia aplicada. Revista do Departamento de Geografia, 16, 81-90. https://doi.org/http://dx.doi.org/10.7154/RDG.2005.0016.0009.

Rosa, R., \& Brito, J. (1996). Introdução ao Geoprocessamento: Sistemas de informações Geográficas (Universidade Federal de Uberlândia, Vol. 1). Uberlândia. Recuperado de http://professor.ufabc.edu.br/ flavia.feitosa/cursos/geo2016/AULA5-

ELEMENTOSMAPA/Apostila_Geop_rrosa.pdf.

Santos, M. (2009). A natureza do espaço: técnica e tempo, razão e emoção (4. ed., 5. reimpr). São Paulo, SP: Edusp, Ed. da Univ. de São Paulo.

Santos, M. (2001). Por uma outra globalização: do pensamento único à consciência universal. $6^{\text {a }}$ ed. Rio de Janeiro: Record. 
Mendes Pontes, E.T., Silva Campos, G., Bezerra de Carvalhoo, A. (2018): “Geotecnologias, cartografia digital e geoprocessamento aplicados ao ensino de geografia e disciplinas afins: uma experiência de extensão no semiárido cearense", GeoFocus (Artículos), no 21, p. 145-167. ISSN: 1578-5157 http://dx.doi.org/10.21138/GF.570

Silva, A., \& Chaves, J. (2011). Utilização do Google Maps e Google Earth no ensino médio: estudo de caso no Colégio Estadual da Polícia Militar-Diva Portela em Feira de Santana-BA (p. 3220-3226). Apresentado em Simpósio Brasileiro de Sensoriamento Remoto (SBSR), Curitiba, Paraná. Recuperado de http://www.dsr.inpe.br/sbsr2011/files/p1657.pdf.

Silva, F. (2015). Google Earth: uma experiência no colégio de tempo integral Maria de Lourdes Vasconcelos (Monografia de graduação em Geografia). Universidade Estadual Vale do Acaraú, Sobral.

Silva, R. (2015). O uso de geotecnologias no suporte metodológico para compreensão do lugar nas aulas de geografia na Escola de Ensino Médio Raimundo da Cunha Brito em Graça - CE (Monografia de graduação em Geografia). Universidade Estadual Vale do Acaraú, Sobral.

Trindade, G. (2012). Globalização, redes e relação mundo - Lugar: insistindo em um debate ainda não esgotado na geografia. Revista GeoNordeste, O(2). Recuperado de https://seer.ufs.br/index.php/geonordeste/article/view/2454 
